\title{
The Effectiveness of the Self-Regulated Learning Model to Improving Student Academic Ability in Mathematics Class
}

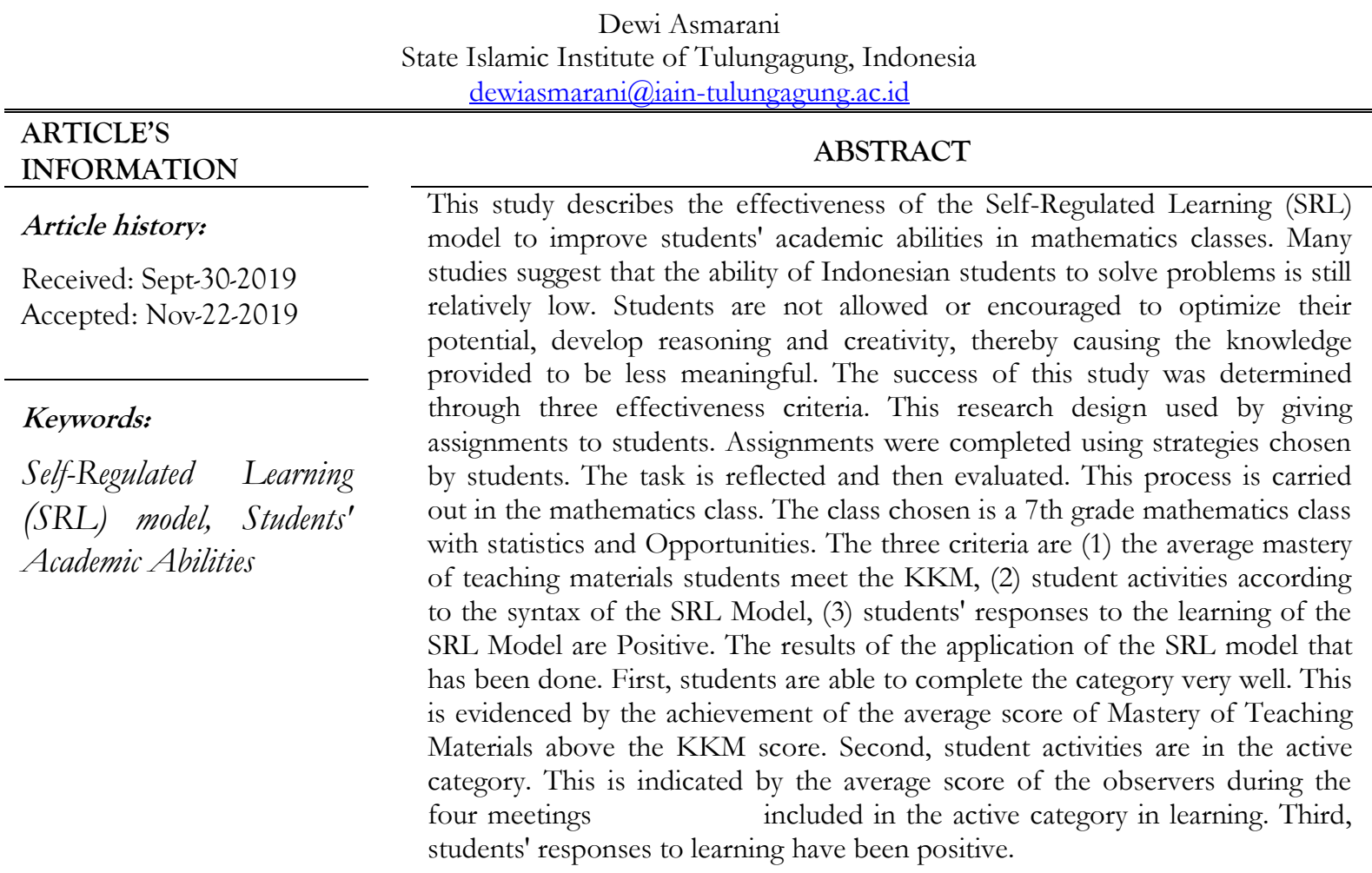

Corresponding address:

Dewi Asmarani

dewiasmarani@iain-tulungagung.ac.id

\section{INTRODUCTION}

Many studies suggest that the ability of Indonesian students to solve problems is still relatively low. The contributing factor is that students are rarely invited to apply the knowledge they have gained to real life problems or students are not familiar with the problems requiring reasoning.[1] Students are rarely given the opportunity to take advantage of reality and their environment in learning. Reality is real or concrete things that can be observed or understood by students through imagining, while what is meant by the environment is where students are located or living either in school, family, or society.

In learning students are positioned as listeners, observers, imitating or imitating exactly the way the teacher provided without the initiative to do the process of finding themselves. Students are not allowed or encouraged to optimize their potential, develop reasoning and creativity, there by causing the knowledge provided to be less meaningful. This means that the knowledge received by students has a tendency to memorize it without the experience of students to apply that knowledge into their daily lives. So that it greatly affects student academic achievement. Therefore a professional teacher must be selective in choosing learning models for the success of the learning process. This is reinforced by the opinion of Saleh, et al who say that Learning process needs to be adjusted such that the abstract objects in mathematics can be represented through concrete objects as a bridge to enter the knowledge that the students already had.[2] 
We know so many learning models, but we must be able to choose the appropriate learning model intelligently. There are several ways you can do to improve students' academic abilities. Among them through learning Self-Regulated Learning, fieldwork Cooperative Learning, Experiential Learning, Computer Aided Instruction, Case Studies, Simulation, Role Playing, Library Tasks, and Peer Tutors. The methods above are very good to do, but special consideration is needed in choosing one of them. One consideration that can be chosen is the consideration of the material and student development. The purpose of this consideration is to facilitate learning. From a number of recommended methods the researcher chose the SelfRegulated Learning Model to enhance students' academic abilities in learning mathematics. The reason from the researcher is Self-Regulated Learning can manage student's learning activities efficiently. [3]

Self-Regulated Learning (SRL) is an individual's ability to examine the learning environment and monitor learning processes to inform decisions about managing learning processes. Under the assumption that learners are agents with inherent capability to make and act on decisions, self-regulated learning (SRL) is ubiquitous.[4] SRL refers to how students become masters of their own learning processes. Neither a mental ability nor a performance skill, selfregulation is instead the self-directive process through which learners transform their mental abilities into task-related skills in diverse areas of functioning, such as academia, sports, music, and health.[5]

Still the same as the above opinion, Zimerman defines Self-Regulated Learning as an individual process in managing thoughts, feelings, and actions and always changes its rotation based on feedback performance that influences the achievement of goals. [6] Zimmerman also define Self-Regulated Learning as learning phases which include: forethough phase, performance phase, and reflection phase. Following is an explanation of each of these phases.

Forethought Phase

There are two categories that are closely interrelated in the planning phase, task analysis and self-motivation beliefs. Task analysis includes setting goals and planning the achievement of goals. Objectives can be interpreted as determining the learning outcomes to be achieved by an individual, for example what students must do when trying to solve mathematical problems. The second form of task analysis is planning. Planning is a process that can be used by someone to achieve the goals set.

Self-motivation beliefs include self-efficacy and outcome expectation. Self-efficacy refers to a person's belief in his ability about the performance he has to achieve his goals. Outcomes expectation refers to individual expectations about the achievement of a result of various efforts he has done. Examples of self-efficacy and outcome expectation are if individuals are confident in their own abilities, the higher the goals they set. They also survive to achieve the goals they have set.

Performance / Volitional Control Phase

In the performance phase the individual implements a completion plan that has been prepared. Individuals concentrate on the task and optimize efforts to achieve the goals set. Individuals monitor specific aspects of performance, surrounding conditions, and the results they produce too.

Reflection Phase 
The essence of this reflection phase is the individual conducts a self-evaluation. Individuals try to compare the information obtained with the goals that have been set to get a right decision.

Individuals give evaluative responses to decide actions, for example, is this good or bad, accepted or rejected, outside or still within the reach of hope.

This SRL is very important for students to have. Students who have SRL are expected to be able to foster an awareness of their learning responsibilities. In addition students who have SRL are aware of what they are doing in learning by understanding why the activity is carried out and what the implications are. Some studies related to this SRL are research conducted by Mega, Carolina, et al. How emotions, self-regulated learning, and motivation contribute to academic Achievement. Data obtained from 5,805 undergraduate students. [7] Zheng, Lanqin saw the effectiveness of self-regulated learning scaffolds on academic performance in computer-based learning environments: a meta-analysis. Research data were obtained from 2648 students. [8] Purposse of the Study

The purpose of this study was to identify the effective self-regulated learning model in learning mathematics to improve students' academic abilities. Specifically, this study investigated the following questions:

"How Self-Regulated Learning (SRL) model to improve students' academic abilities in mathematics classes?"

\section{METHOD}

This research design used by giving assignments to students. students and teachers established an understanding of the task, defined task goals, and then, using task goals as a foundation for decision making, selected, adapted, or invented task-specific strategies. Factors that go into the decision making about strategies also included the specific difficulties students had with the task, students' processing strengths and weaknesses, and students' preferences. Subjek

The class chosen is a 7Ath grade mathematics class in SMPN I Singosari. This class is chosen randomly from nine math classes that have been registered in 2018. The number of students in the class is 30, while the material being tested is statistics and Opportunities.

Measures

To see the effectiveness of the SRL model researchers used the following 3 conditions: (1) the average Mastery of Teaching Materials students meet the KKM, (2) student activities according to the SRL Model phase, (3) students' responses to the learning of the SRL Model are Positive.

\section{RESULT AND DISCUSSION}

Result

Mastery of Teaching Materials

Mastery of Teaching Materials consists of two aspects. First is the results of the Teaching Material Mastery Test. the second is the grade from the Student Worksheet. The results of the mastery test are given a weighting of $60 \%$ and the work of the Student Worksheet is given a weight of $40 \%$. Because there are four meetings, the results of the Student Worksheet scores and the mastery test scores of individual teaching materials are determined by taking an average of 
both. The recapitulation results of the Student Worksheet and the mastery of teaching materials for the whole class for both aspects are presented in the table below.

Table 1. Recapitulation of Mastery of Teaching Materials

\begin{tabular}{|l|c|c|c|}
\cline { 2 - 4 } \multicolumn{1}{c|}{} & LKS & TPBA & Mastery of Teaching Materials \\
\hline Rata-rata kelas & 77.5 & 85.5 & 81.5 \\
\hline
\end{tabular}

Note: TPBA: Teaching Material Mastery Test

\section{Student Activities}

Student activity is obtained from the assessment based on the Student Activity Observation Sheet. Based on the results of the analysis of student activity in the SRL Model, the average score of student activity from 2 observers was 2.765 . Thus it can be concluded that students are active in learning because the scores are in the range of 2 to 3. Based on the results of the analysis of student activity the SRL Model for each meeting obtained an average score of two observers at Meeting I was 2,625, Meeting II was 2,685, in Meeting III it is 2.75 , and in Meeting IV it is 3. This shows that in all four meetings, students actively participated in learning. However, it still needs to be explored student activities which according to observations need to be optimized.

Student Response

Based on the analysis of student responses to the SRL Model learning, $80 \%$ of students gave a positive response to the SRL Model learning. In addition, students have understood the concepts that have been taught. These concepts are Statistics concepts and Opportunities. Students also understand the learning objectives and plans that he must do to achieve these goals. Students also try to always evaluate their work.

Discussion

The results of the Student Worksheet have an average value of 77.5. The test results of mastery of teaching materials have an average value of 85.5. Classically, the average value of mastery of teaching materials is $81.5>75$. This means that students' mastery of teaching materials can be categorized as having exceeded the KKM value. The above results clearly show that the SRL model influences students' academic abilities. The same thing was also conveyed by Mega et al. The structural equation model showed that students' emotions influence their self-regulated learning and their motivation, and these, in turn, affect academic achievement. Thus, selfregulated learning and motivation mediate the effects of emotions on academic achievemen. [7]

In student's activities, some students still have difficulty making connections between the information obtained and the problems they are facing. This happens because they do not know the purpose of learning. Though learning goal setting is the main thing to do. Learners' motivations and goals were found to shape how they conceptualised the purpose of the learning, which in turn affected their perception of the learning process. [9] Beside that, some students are still wrong in carrying out the plans they have grawn up. This is marked by frequently removing the results of the answers he gets. This shows that self-confidence is low. This can be overcome if students are accustomed to solving contextual problems, because students' self-confidence taught by contextual learning model is higher than students taught by expository learning. [10] Self-efficacy affects individual performance. This also affects his motivation. Thus, it becomes necessary to identify the practical implications of the outcomes related to improving self-efficacy in order to motivate them and improve their performance. [11] 
The application of the SRL model in mathematics classrooms is able to foster positive student attitudes. Some positive attitudes that arise in students are willing to take mathematics learning in class, like learning mathematics in class, trying to learn mathematics material deeper, trying to solve mathematical problems / problems optimally even though these problems are classified as very difficult, and try to apply their knowledge in solving problems in daily life. This is the same as the opinions of Zhao, Hong and Chen, Li who said that SRL has elicited considerable interest. Self-regulated learners can manage their learning activities efficiently. [3]

\section{CONCLUSIONS AND SUGGESTION}

\section{Conclusions}

The results of the application of the SRL model that has been done, there are some conclusions that can be drawn, especially related to the effectiveness of this model. First, related to the Mastery of Teaching Materials. Students are able to complete the category very well. This is evidenced by the achievement of the average score of Mastery of Teaching Materials above the KKM value. Second, student activities are in the active category. This is indicated by the average score of the observers during the four meetings included in the active category in learning. Third, students' responses to learning have been positive. Because all three criteria have been fulfilled, it can be said that the SRL Model is very effective for improving students' abilities in mathematics classes.

Suggestions

Some students still have difficulty making connections between the information obtained and the problems they are facing. Furthermore, other researchers are expected to find specific strategies to find the right way to overcome the problem.

\section{REFERENCE}

[1] R. Johar, S. Yusniarti, and Saminan, "The analysis of proportional reasoning problem in the Indonesian mathematics textbook for the junior high school," J. Math. Educ., vol. 9, no. $1,2018$.

[2] M. Saleh, R. C. I. Prahmana, M. Isa, and Murni, "Improving the reasoning ability of elementary school student through the Indonesian realistic mathematics education," J. Math. Educ., vol. 9, no. 1, 2018.

[3] H. Zhao and L. Chen, "Self-regulated learners can manage their learning activities efficiently but researchers indicate that learners have difficulties in SRL behavior. Thus, providing support to facilitate self-regulatory processes is important. E-learning has the potential t," J. Educ. Technol. Dev. Exch., vol. 9, no. 2, Dec. 2016.

[4] P. H. Winne, "Self-Regulated Learning," in International Encyclopedia of the Social \& Behavioral Sciences: Second Edition, 2015.

[5] B. J. Zimmerman, "Self-Regulated Learning: Theories, Measures, and Outcomes," in International Encyclopedia of the Social \& Behavioral Sciences: Second Edition, 2015.

[6] B. J. Zimmerman, "Changing Conceptions of Individual Differences," vol. 41, no. 2, pp. 64-70, 2002.

[7] C. Mega, L. Ronconi, and R. De Beni, "What makes a good student? How emotions, selfregulated learning, and motivation contribute to academic Achievement," J. Educ. Psychol., 2014. 
[8] L. Zheng, "The effectiveness of self-regulated learning scaffolds on academic performance in computer-based learning environments: a meta-analysis," Asia Pacific Educ. Rev., 2016.

[9] A. Littlejohn, N. Hood, C. Milligan, and P. Mustain, "Learning in MOOCs: Motivations and self-regulated learning in MOOCs," Internet High. Educ., 2016.

[10] E. Surya, F. A. Putri, and Mukhtar, "Improving mathematical problem-solving ability and self-confidence of high school students through contextual learning model," J. Math. Educ., vol. 8 , no. 1, 2017.

[11] J. Cherian and J. Jacob, "Impact of Self Efficacy on Motivation and Performance of Employees," Int. J. Bus. Manag., 2013.

\section{BIOGRAPHY}

Dewi Asmarani

Ade Irma Suryani Kindergarten Singosari-Malang, (1981). Candirenggo 4 Elementary School Singosari-Malang, (1983). Elementary Middle School 1 Singosari-Malang, (1989). Elementary High School 1 Lawang-Malang, (1992). S1 Mathematics Education in State University of Malang, (1996). S2 Mathematics Education in State University of Malang, (2003). S3 Mathematics Education in State University of Malang, (2010). Lecture in State Islamic Institute of Tulungagung, Indonesia 